\title{
Diagnosis of hypothyroidism depending upon signs and symptoms design scoring system
} Fadel Abass Al-seidi ${ }^{1}$

\author{
${ }^{1}$ University of Thi-Qar College of medicine \\ ${ }^{2}$ University of Thi-Qar College of sciences department of biology
}

\section{Summary}

Hypothyroidism may occur as a result of primary gland failure or insufficient thyroid gland stimulation by the hypothalamus or pituitary gland. It also occur when using radio-iodine. Study extended for about 2012-2013, in Thi-qar city hospital and private clinic in Republic of Iraq. 40 patients (31 women and 9 men) of suspected hypothyroidisms considered in the study. 38 patients were diagnosed as hypothyroidisms after laboratory testing of patients with thyroid function tests (TSH and T4). All of them are a positive results while the other 2 patients got negative results to TFT. According to this results we design the scoring system depending on signs and symptoms that we find in the patients. concord between above results and our system, patients get more than 12 points diagnosis as hypothyroidism, and who get less than 12 point consider non hypothyroid.

$\underline{\text { الخلاصة }}$

يرتبط مرض نقص افراز الغدة الدرقة بحالات نقص اليود او ازالة الغدة جراحياً او استخدام اليود المشع كذللك الاضطرابات التي تصيب الغده النخامية

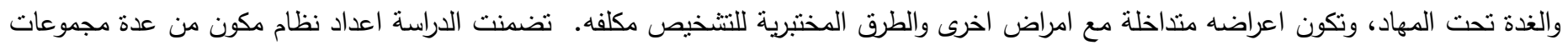

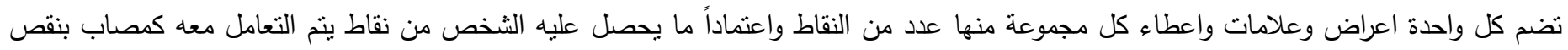

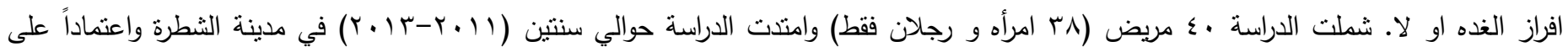

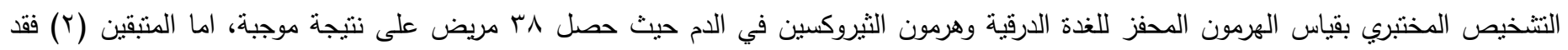

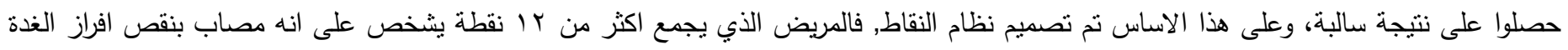

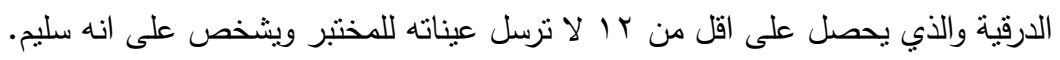

\section{Introduction}

Normal thyroid function involves a complex system with multiple interconnected physiological processes and an essential feedback mechanism. First, the hypothalamus secretes thyrotropin-releasing hormone (TRH), which triggers the anterior pituitary gland to synthesize and release thyroid-stimulating hormone (TSH). In turn, the thyroid gland produces and releases thyroxine (T4) and triiodothyronine (T3). Thyroid hormones help regulate metabolism and play an integral part in growth, brain development, and many functions of the cardiovascular, nervous, and reproductive systems (1). Most T3 and T4 hormones are bound to plasma proteins, leading to the term free to refer to the bioavailable amounts that are not bound. Through a negative feedback mechanism, the circulating thyroid hormones suppress the amount of TRH and TSH secreted, causing inhibition of $\mathrm{T} 3$ and $\mathrm{T} 4$ production. Hypothyroidism occurs from either a breakdown at any point in the hypothalamus-pituitary-thyroid feedback system or from a defect in hormone synthesis and release from the thyroid gland (2). While iodine deficiency is the leading cause of hypothyroidism worldwide, the most common etiology in North America is an autoimmune disorder known as Hashimoto's thyroiditis $(2,1)$. This autoimmune process involves a slow progressive decline in thyroid function (1).Also, certain medications diminish hormone synthesis, inhibit release of thyroid hormones, or interfere with components of the hypothalamicpituitary-thyroidfeedback mechanism. All of these effects can result in hypothyroidism. Drugs that may decrease TSH levels include glucocorticoids, opiates, and dopamine (2). Other medications, such as amiodarone, chemotherapy agents, lithium, and cytokine blockers, diminish secretion of thyroid 
hormones $(\underline{2}, \underline{3})$. Due to underlying chronic conditions, older adults tend to take many of the medications that can contribute to the development of hypothyroidism (3). Atypical clinical presentations of hypothyroidism can include hypothermia, (4) congestive heart failure, $(5,6)$ pericardial $(7,8)$ and pleural effusions(9) ileus and intestinal pseudoobstruction,(10)andcoagulopathy(11). Neurological manifestations can include depression (12). psychosis,(13,14) ataxia (15). seizures (16) and coma.(17). Hypothyroidism has been associated with several neurocognitive deficits, particularly in memory.(18). Other signs include dry skin, cold intolerance, yellow skin, coarseness or loss of hair, hoarseness, goiter, Reflex delay,relaxation phase, ataxia, constipation, and mental impairment, also decreased concentration, depression, irregular or heavy menses and infertility, myalgias, hyperlipidemia,bradycardiaand ypothermia $(19,20)$

Myxedema fluid infiltration of tissues The condition has traditionally been included in the differential diagnosis of reversible dementias and is occasionally seen in elderly patients with dementia, but thyroid hormone treatment rarely reverses dementia in these individuals. $(16,17)$.Symptoms of hypothyroidism may vary with age and sex. Infants and children may present more often with lethargy and failure to thrive. Women who have hypothyroidism may present with menstrual irregularities and infertility. In older patients, cognitive decline may be the sole manifestation. The clinical presentation is often confused with septic shock. Myxoedema coma, which represents severe physiologic decompensation resulting from hypothyroidism, occurs rarely, with an annual incidence of 0.22 per million (9). Laboratory findings in hypothyroidism may include hyponatraemia, hypercapnia, hypoxia, normocytic anaemia, elevated creatine kinase, hyperprolactinaemia, and hyperlipidaemia.(21).

\section{Method}

The study extend for about two years from (July 2011- June 2013).Forty patients were examined in Alshatrah hospital Thi-qar city, Iraq and private clinic in the same city. Patients ages were (18-33 year) 23 person, (34-42year) 14 person, (43-56year) 3 persons. Sex of them was (31 women and 9 men). Diagnosis of hypothyroidism is by testing of thyroid stimulation hormone (TSH) and T4 hormone concentration in the blood. after getting results of laboratory tests we design scoring system. According to the frequency of known clinical features in our studied patients in table (1).
Table (1) clinical signs and symptoms and scoring values related

\begin{tabular}{|c|c|}
\hline Signs and symptoms & Score \\
\hline thick dry skin \&coarse features & 4 \\
\hline hoarse voice & 3 \\
\hline delayed relaxation phase of the ankle jerk & 2 \\
\hline delayed relaxation phase of the ankle jerk & 2 \\
\hline periorbital edema & 1 \\
\hline $\begin{array}{c}\text { weight gain (more than 6 kg increase in the body } \\
\text { weight) }\end{array}$ & 2 \\
\hline bradycardia & 2 \\
\hline $\begin{array}{c}\text { constipation } \\
\text { Depression,Goiter, hypertension }\end{array}$ & 2 \\
\hline
\end{tabular}

\section{$\underline{\text { Results }}$}

From total 40 patients that send to laboratory tests, 38 patients get positive results (they showed increase level of TSH and low or less normal level of T4 in blood). 2 patients gave negative results. According to scoring system that we designed patient get more than 12 point consider as hypothyroidism, while the patient get less than 12 points of scoring system consider as non-hypothyroidism. With time such figures were modified according to the appearance of new clinical features of each patient. The results according to scoring system for the diagnosis of hypothyroidism were demonstrated in Table (2).

Table 2 numbers of patients revealed signs and symptoms of suspected hypothyroidism and related scoring system at the time of first evaluation

\begin{tabular}{|c|c|c|}
\hline $\begin{array}{c}\text { Number } \\
\text { of } \\
\text { patients }\end{array}$ & Signs and symptoms & Score \\
\hline 38 & thick dry skin\& coarse features & 4 \\
\hline 35 & $\begin{array}{c}\text { slow relaxation phase of ankle } \\
\text { jerk\& hoarseness of the voice }\end{array}$ & 3 \\
\hline 31 & weight gain of more than 6kgs & 2 \\
\hline 31 & $\begin{array}{c}\text { deepening of the voice\& slow } \\
\text { speech rhythm. }\end{array}$ & 2 \\
\hline 17 & bradycardia & 2 \\
\hline 11 & periorbital edema\& constipation & 1 \\
\hline 23 & miscellaneous manifestations & 2 \\
\hline
\end{tabular}




\section{Discussion}

Manyclinical manifestations of hypothyroidism are non-specific and often attributed to aging, most of elderly people normally have signs may be confused with disorder of thyroid gland (3).This study revealed that prevalence of this disease in young ages more than elderly and this is concord with previous studies which proved that prevalence of hypothyroidism was high in the 30-to-39-year age group, which was $16 \%$. This contrasts with $8.66 \%$ for the 50-to-59-years old, and $1.33 \%$ for 60 -to-69-years old (22).Scoring system of the signs and symptoms of hypothyroidism is helpful in the diagnosis of hypothyroidism. Most physicians in their clinics send their patients to laboratory for diagnosis of the disease when they have suspension of any case as hypothyroidism which is too much expensive to sick people and take time to diagnosis, but by following the scoring system that we designed it that will switch on light to the physicians to make primary diagnosis of thyroid disorder not mixed with other diseases hardly differentially diagnostic and then send only the patients who are getting high points of the system, ultimately decrease money cost and time for absolute diagnosis. Our study compatible with another one in India which was depended on clinically scoring system to diagnosed hypothyroid and it recommended in countries where resources are limited, this scoring system can improve the clinical evaluation of patients who have one or more symptoms of hypothyroidism and reduce the load on referral centers (23).

\section{References}

1-Jameson, J.L. \& Weetman, A.P. Disorders of the thyroid gland. In Longo, D., Fauci, A., Kasper, D., Hauser, S., Jameson, J. \& Loscalzo, J. (Eds.), Harrison's principles of internal medicine (2012). (18th ed., pp. 2911-2939. New York: McGrawHill.

2-Almandoz, J.P. \& Gharib, H. Hypothyroidism: Etiology, diagnosis, and management. Medical Clinics of North America, 96, 203-221. doi:10.1016/j.mena.(2012).pp:01.005

3-Biondi, B. \& Cooper, D.S. The clinical significance of subclinical thyroid dysfunction. Endocrine Reviews, 29, 76-131. doi:10.1210/er.(2008). pp: 2006-2043

4-Tachman, ML, Guthrie, GP. Hypothyroidism: diversity of presentation. Endocr (1989). Rev; 5:pp: 456-65.
5- Reuler, JB. Hypothermia: pathophysiology, clinical settings, and management. Ann Intern Med ;(1974). 89: pp: 519-27.

6- Zondek, H. Das Myxdemherz. Münch Med Wochenschr ; (1914). 65: 1180-83.

7- Ladenson, PW, Sherman SI, Baughman KL, Ray PE, and Feldman AM. Reversible alterations in myocardial gene expression in a young man with dilated cardiomyopathy and hypothyroidism. Proc Natl Acad Sci USA ;(1992). 89: 5251-55.

8- Quin, JD., McDonald, A., Russell, R., and Thomson, JA. Hypothyroidism presenting with cardiac tamponade. Scott Med J (1994); 39: 82.

9-Lin CT., Liu CJ., Lin, TK., Chen, CW., Chen, BC., and Lin, CL. Myxedema associated with cardiac tamponade. Jpn Heart J ;(2003) 44: 447-50.

10- Gottehrer, A, Roa J, Stanford GG, Chernow B, and Sahn SA. Hypothyroidism and pleural effusions. Chest ;(1993) 98: 1130-32.

11- Boruchow, IB, Miller LD, and Fitts WT Jr. Paralytic ileus in myxedema. Arch Surg ; (1964).92: 960-63.

12- Edson JR, Fecher DR, and Doe RP. Low platelet adhesiveness and other hemostatic abnormalities in hypothyroidism. Ann Intern Med ; (1975).82: 342-46.

13- Jackson, IM.The thyroid axis and depression. Thyroid (1996).; 951-56.

14- Logothetis, J. Psychotic behavior as the initial indicator of adult myxedema. J Nerv Ment (1963).Dis ; 136: 561.

15- Price, TR. and Netsky, MG. Myxedema and ataxia: cerebellar alterations and "neural myxedema bodies". (1966). Neurology ; 16: 957-62.

16- Woods, KL. and Holmes, GK. Myxoedema coma presenting in status epilepticus. (1977). Postgrad Med J ; 53: 46-48.

17-Nicoloff JT. and LoPresti JS. Myxedema coma: a form of decompensated hypothyroidism. (1993). Endocrinol Metab Clin North Am ; 22: 279-90.

18- Nickel, SN, Frame B. Neurological manifestations of myxedema. (1953). Neurology; 8: 511.

19-Clarnette, RM, and Patterson, CJ. Hypothyroidism: does treatment cure dementia? (1994). J Geriatr Psychiatry Neurol ; 7: 23-27.

20- Dugbartey, AT. Neurocognitive aspects of hypothyroidism. (1998). Arch Intern Med ; 158: 1413-18.

20- Utiger, RD. Hypothyroidism. In: DeGroot LJ, ed. Endocrinology. Vol 1. 2nd ed. Philadelphia: WB Saunders Co,(1998). pp: 702-721. 
21. Larsen, PR., Davies TF. and Hay ID. The thyroid gland. In: Wilson JD, Foster DW, Kronenberg HM, Larsen PR, eds. Williams Textbook of Endocrinology. 9th ed. Philadelphia: WB Saunders Co, (1998). pp: 389-515.

22- Skaria, L.K., Agnihotram, G. Thakur, A.S. and Pamidamarri, G. Thyroid dysfunctions in women of Bastar. (2011). Thyroid Science, 6(6), pp:1-5.

23- Seshadri, M.S.; Benjamin U.S. and Kanagasabapathy, A.S. Clinical scoring system for hypothyroidism. (1989).Volume 4, Issue 6, pp 490-492. 